UDC 622.06

DOI: $10.15587 / 2706-5448.2021 .246604$

Article type «Reports on Research Projects»

\title{
Oleh Zimin
}

\section{IMPROVEMENT OF ACID SOLUTIONS FOR STIMULATION OF COMPACTED HIGH-TEMPERATURE CARBONATE COLLECTORS}

The object of research in this work is the intensification of hydrocarbon production. The most problematic task of the study is the efficiency of intensification of compacted high-temperature carbonate reservoirs. Despite the gradual transition to renewable energy sources, natural gas and oil will play a dominant role in the world's energy balance in the next 20-30 years. Carbonate rocks have significant mining potential, but low filtration properties require intensification to improve reservoir permeability. High temperatures and pressures at great depths require the improvement of existing hydrocarbon production technologies. The most popular method for treating reservoirs containing carbonates is acid treatments in different variations, but for effective treatment it is necessary to achieve deep penetration of the solution into the formation.

The study solves the problem of selection of effective carrier liquids for the preparation of acid solutions for the treatment of compacted high-temperature reservoirs with high carbonate content. To ensure quality treatment, acid solutions must have low viscosity and surface tension coefficient, low reaction rate, their chemical properties must ensure the absence of insoluble precipitates in the process of reactions with fluids and rocks, as well as be environmentally friendly. To select the most optimal carrier liquid, experiments were conducted to determine which candidate liquids provide the minimum reaction rate of acidic solutions with carbonates. Based on the analysis of industrial application data and literature sources, water, nephras, methanol, ethyl acetate, and methyl acetate were selected for further research. Widely studied acetic acid was chosen as the basic acid. Studies have shown that methyl acetate has a number of advantages, namely low reaction rate, low viscosity and surface tension coefficient. As well as the possibility of hydrolysis in the formation with the release of acetic acid, which significantly prolongs the reaction time of the solution with the rock and the depth of penetration of the active solution into the formation.

Keywords: carbonates, compacted rocks, methyl acetate, acetic acid, well intensification, acid solutions.

Zimin, O. (2021). Improvement of acid solutions for stimulation of compacted high-temperature carbonate collectors. Technology Audit and Production Reserves, 6 (3 (62)), 11-14. doi: http://doi.org/10.15587/2706-5448.2021.246604

\section{Introduction}

The global strategy for the development of the energy sector, related to the «green transition», today requires new approaches to this issue by scientists around the world. Even with the efficient and consistent introduction of renewable energy sources in the future, natural gas and oil will play a dominant role in the world's energy balance in the next 20-30 years. In most developed countries of the world, the issue of providing energy resources for one's own needs is quite acute, especially in the case of oil and gas. Old deposits are rapidly depleting, which requires research of ever greater depths with significant formation pressures and temperatures, low filtration-capacity characteristics. Significant prospects for increasing oil and gas production opportunities are the possibility of developing compacted rocks, including carbonate $[1,2]$. Operators often do not see low-permeability carbonate deposits as promising for oil or gas production due to difficult development conditions. Low filtration properties require intensification to improve the permeability of the bottomhole zone, but high temperatures and pressures at depths of more than 5,000 meters require improvement of existing hydrocarbon production technologies.

Carbonate rocks are soluble in most acids, but the choice of effective intensification technology depends on many factors. The main problem for most deep-lying rocks is insufficient penetration of acid solutions due to low permeability of the rock. The acid reacts with the rock, not reaching a sufficient depth to improve the filtration properties. The high temperature of the deposits causes a rapid reaction of acidic solutions with the rock [3], which leads to the formation of deep cavities in the bottomhole zone of the formation, therefore the solution cannot penetrate deep into the formation and form an extensive network of channels. 
The most popular method for treating reservoirs containing carbonates is hydrochloric acid treatments in various variations, but for treating carbonate high-temperature rocks with low permeability, these treatments are not effective even with inhibitors. Acidic solutions based on carboxylic acids are more suitable for such treatments, which react much more slowly at high temperatures and do not require the use of a large number of reaction and corrosion inhibitors [4]. However, for effective treatment it is necessary to achieve deep penetration of the solution into the formation and create an extensive network of channels in the treatment area. The use of water-based acid solutions is not effective because the viscosity of such a solution is too high for filtration in a low-permeability reservoir.

Therefore, the urgent task is to develop new intensification fluids that will effectively develop hydrocarbon deposits at great depths. The most problematic issue of the study is the effectiveness of intensification under conditions of high temperature and low permeability.

Therefore, the object of research in this paper is the intensification of hydrocarbon production. The aim of research is to select effective carrier fluids for the preparation of acid solutions for the treatment of compacted high-temperature reservoirs with high carbonate content.

\section{Methods of research}

To ensure high-quality treatment of compacted hightemperature carbonate reservoirs, acid solutions must have low viscosity and surface tension coefficient, low reaction rate. The chemical properties of solutions must ensure the absence of insoluble sediments in the process of reactions with fluids and rocks, as well as be environmentally friendly.

To select the most optimal carrier liquid, let's conduct an experiment that will determine which candidate liquids provide the minimum reaction rate of liquids with carbonates. Based on the analysis of data on industrial applications [5] and literature sources [6, 7], let's choose several types of carrier liquids for further research:

- water - basic (standard) solvent;

- nephras 80/120 - analog of gas condensate, effective

solvent in the treatment of oil and gas condensate wells;

- methanol - widely studied in industry and laboratory research;

- ethyl acetate and methyl acetate are science-based solvents that have low viscosity and surface tension, and therefore significant mobility in the formation.

The study is to determine the solubility of acid solutions over time depending on the solvent and the temperature of the solution (experiment 1).

As a basic variant of acid in the study let's use acetic (ethanoic) acid $[4,8,9]$ repeatedly described in the lite- rature at a concentration of $20 \%$ in solution with a carrier. The main advantages of acetic acid are low reaction rate, which is important for high-temperature collectors, high stability, compatibility with basic solvents.

Therefore, 5 solutions were prepared for the experiment:

- S1. $20 \%$ acetic acid $+80 \%$ water;

- S2. $20 \%$ acetic acid $+80 \%$ nephras $(80 / 120)$;

- S3. $20 \%$ acetic acid $+80 \%$ methanol;

- S4. $20 \%$ acetic acid + $80 \%$ ethyl acetate;

- S5. $20 \%$ acetic acid + $80 \%$ methyl acetate.

Investigation of the reaction rate of solutions with carbonates is carried out on plates of crystallized limestone with a mass of $2.4 \mathrm{~g}$, with a plate surface area of $8.8 \mathrm{~cm}^{2}$. The rock samples contain $96 \%$ calcite, $1.5 \%$ dolomite, $1.6 \%$ silicon oxide, up to $0.6 \%$ siderite, as well as minor inclusions (up to $0.1 \%$ ) of kaolinite, montmorillonite, manganese and aluminum compounds.

Place the plates in flasks, then add to each $9 \mathrm{~cm}^{3}$ of solution. Monitor the reaction rate over time (for 2 hours) at different temperatures (at $20^{\circ} \mathrm{C}$ and when heated to $50{ }^{\circ} \mathrm{C}$ ). For each solution and temperature let's conduct 4 studies (a total of 40 studies to select the carrier fluid). After a series of experiments and statistical processing of the results, the average values for each test fluid are entered in Table 1.

From the Table 1 it is possible to see that the lowest reaction rate at elevated temperature is in solutions based on acetic acetate. Therefore, for further research as a carrier fluid, let's choose methyl acetate as the most promising. Conduct an additional series of time-dependent reaction rate studies (experiment 2) for solutions S1 (basic) and S5 (promising) on plates of limestone crystallized with a mass of $2.4 \mathrm{~g}$. Place the plates in flasks, then add to each $9 \mathrm{~cm}^{3}$ of solution. Monitor the reaction rate over time at $20^{\circ} \mathrm{C}$. Measure the decrease in sample weight after one, two and four hours for each solution. For the reliability of the results, each group of studies is repeated three times (a total of 18 studies).

The last step was to conduct a series of studies on the intensity of the reaction by measuring the amount of carbon dioxide released during the reaction of acids with calcium carbonate in a carbonate meter (experiment 3) at a temperature of $20{ }^{\circ} \mathrm{C}$. Chalk samples from the Volcheyar Cretaceous quarry of the following composition were used: compounds of calcium $97-98 \%$, silicon $1.2-1.9 \%$, iron $0.3-0.6 \%$, manganese up to $0.15 \%$; other impurities less than $0.1 \%$. The study included loading a $2 \mathrm{~g}$ chalk plate into a closed reactor, and a beaker with an acid solution $(8 \mathrm{ml})$ was placed in this reactor. After sealing the reactor, it is inverted, thus stirring the contents. The reaction of the acid with calcium carbonate begins, the release of carbon dioxide is recorded by changing the pressure in the reactor with a connected manometer.

The average values of the results of the study of the reaction of limestone samples with acidic solutions

\begin{tabular}{|c|c|c|c|c|c|}
\hline Solution number & Initial mass of samples, mg & $\begin{array}{c}\text { Final mass of the } \\
\text { sample at } 20^{\circ} \mathrm{C}, \mathrm{mg}\end{array}$ & $\begin{array}{c}\text { Final mass of the } \\
\text { sample at } 50^{\circ} \mathrm{C}, \mathrm{mg}\end{array}$ & $\begin{array}{c}\text { Decrease in mass } \\
\text { at } 20^{\circ} \mathrm{C}, \%\end{array}$ & $\begin{array}{c}\text { Decrease in mass } \\
\text { at } 50^{\circ} \mathrm{C}, \% \\
\end{array}$ \\
\hline 51 & 2400 & 2218 & 2005 & 7.58 & 16.45 \\
\hline 52 & 2400 & 2332 & 2278 & 2.83 & 5.08 \\
\hline 53 & 2400 & 2338 & 2286 & 2.58 & 4.75 \\
\hline 54 & 2400 & 2347 & 2309 & 2.21 & 3.79 \\
\hline $\mathbf{5 5}$ & 2400 & 2348 & 2304 & 2.17 & 4 \\
\hline
\end{tabular}

Note: the most promising solution for further research is highlighted in bold 
S1 and S5 solutions were used in the study, and inhibited hydrochloric acid solution (hydrochloric acid content $15 \%$ ) was used for comparison. In addition, to study the dependence of the reaction rate on the water content in the porous medium, the chalk plates in the study of the solution S5 contained $10 \%$ or $30 \%$ moisture. A total of 12 measurements were performed - three experiments for each solution.

\section{Research results and discussion}

Analyzing the results of studies (experiment 1) on the selection of an effective carrier fluid for acidic solutions (Table 1), it was concluded that the greatest efficiency of the solution based on methyl acetate (S5). First, the reaction rate under normal conditions and at elevated temperature in solution S5 is the lowest. Second, the viscosity of methyl acetate is the lowest among the candidate liquids (0.36 MPa.s), and therefore the liquid has better filtration properties in a low-permeability reservoir than others. Third, methyl acetate is easily hydrolyzed in contact with water to form methanol and acetic acid, which will allow to obtain acid directly in the formation, which will further increase the efficiency of processing.

Comparative analysis of the reaction rate over time (experiment 2) of the basic solution (S1) with the selected (S5) shows that the methyl acetate solution reacts slowly with the rock within 4 hours of the study, while the basic solution almost completely loses its activity after two hours (Fig. 1).

Analysis of the study shows that in addition to the delayed reaction, it is affected by the chemical properties of methyl acetate. Under the action of acidic environment, elevated temperatures and in the presence of water, methyl acetate is hydrolyzed to form methanol and acetic acid, as a result of which additionally released acetic acid reacts with carbonates [10]. This indicates the importance of the presence of rock water in the pore space, including bound.

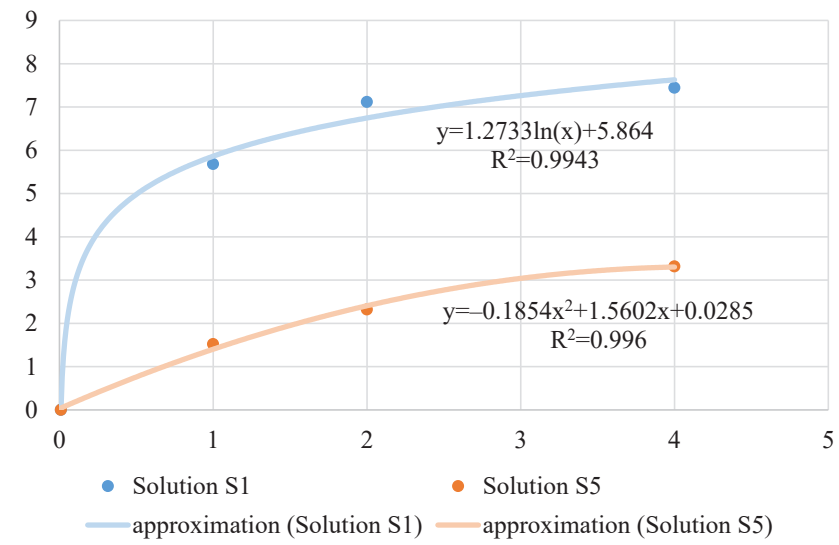

Fig. 1. Graph of the dependence of the solubility rate of the sample on the reaction time

Analysis of the results of studies of the reaction rate of chalk plates with acid solutions (experiment 3) in a closed reactor shows (Fig. 2) that in comparison with the basic solution S1 the reaction rate of solution S5 is several times lower. Compared with the hydrochloric acid solution, the reaction rate is an order of magnitude lower, and the reaction of hydrochloric acid with sample 1 is almost complete in three minutes.

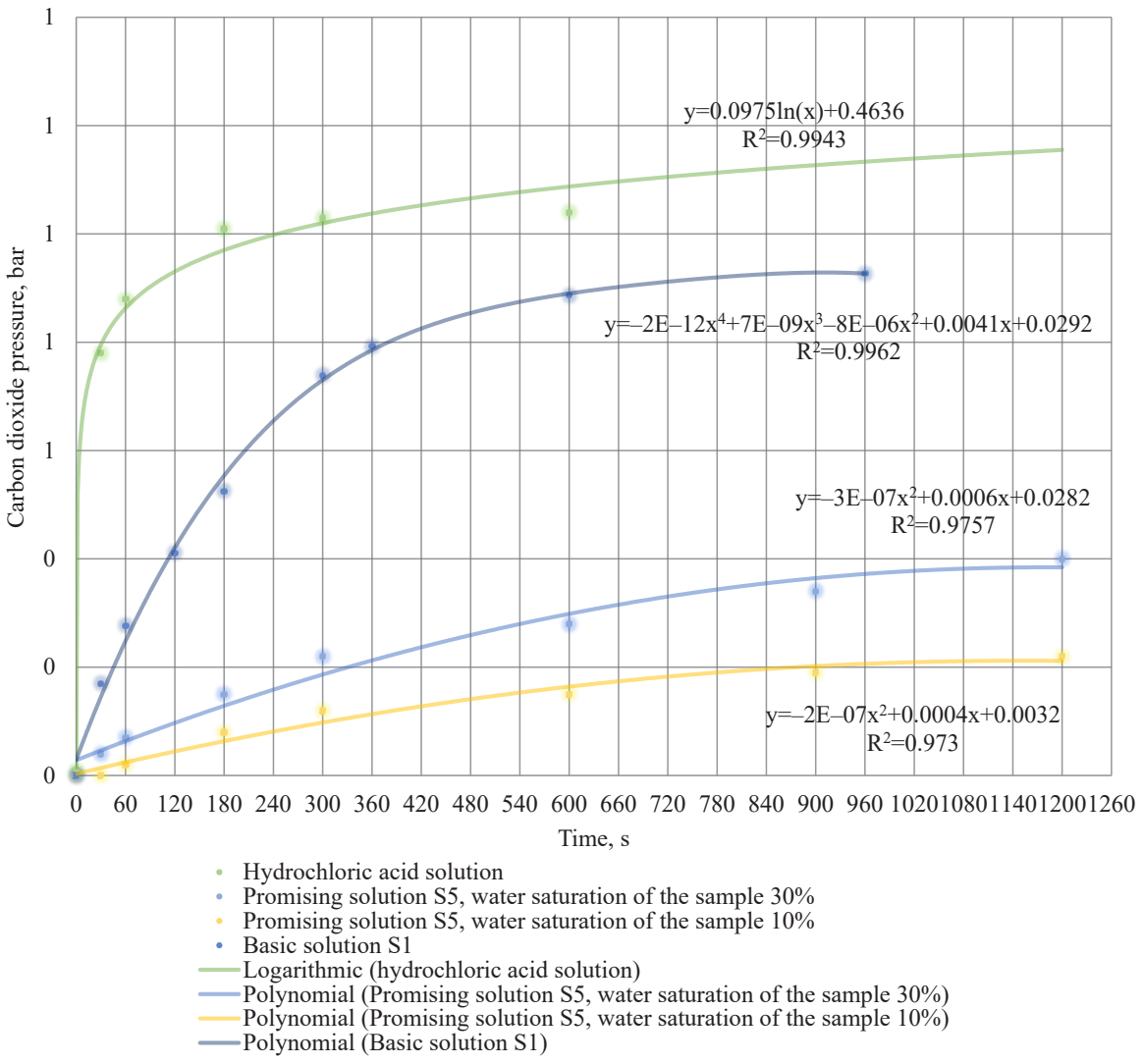

Fig. 2. Efficiency of dissolution of carbonate rock in time by carbon dioxide release 
The chalk samples in the carbonate range of the promising S5 solution had a water saturation of $30 \%$ and $10 \%$, respectively, and a more intense reaction can be seen with a sample of $30 \%$ water saturation. This is quite natural, because water is a kind of «catalyst» of the reaction, in addition, after exhausting all the acetic acid from solution, in the presence of water, hydrolysis of methyl acetate to methanol and acetic acid, which continues to react with the rock.

The absolute values of the research results are valid for the above research conditions and the samples used, as the impact of various impurities in real rock can be quite significant. Important results of the study are the relative rates of duration, duration and intensity of the reaction of different samples of solutions with rocks of the same composition.

To confirm the effectiveness of the developed acid solutions, further studies based on methyl acetate and carboxylic acids should be performed on the cores of compacted carbonate rocks in formation conditions using high pressure and temperature filtration units (HTHP).

\section{Conclusions}

The study showed that in order to intensify the extraction of oil and gas from compacted low-permeability high-temperature carbonate reservoirs, it is necessary to develop acid solutions that would meet modern requirements for the development of deep hydrocarbon deposits. This requires solutions with low viscosity, low surface tension, slow reaction rate with the rock. Based on the analysis of industrial data and literature sources for the development of an effective intensification solution, 5 carrier liquids were studied: water, nephras 80/120 (analog of gas condensate), methanol, ethyl acetate and methyl acetate. Methyl acetate was chosen as the most promising. According to studies, solutions based on methyl acetate and acetic acid have four times lower reaction intensity at $50{ }^{\circ} \mathrm{C}$ than the basic solution (4\% dissolution of carbonate solution S5 vs. $16.45 \%$ - in solution S1). Methyl acetate also has the lowest viscosity (0.36 MPa.s) and surface tension coefficient among the potential carrier fluids studied. This will allow the solutions to penetrate deep into the bottomhole zone of the well, and create an extensive network of channels. In contrast to fast-reacting solutions, the efficiency of which is lost at high temperatures near the bottom of the well developed promising solutions based on methyl acetate react with the rock for several hours (up to 4 hours in the study), the reaction of hydrochloric acid solution 5-10 minutes, basic acid solution S1 - up to 2 hours. The long reaction time makes it possible to inject the active acid solution into the reservoir for several meters, even if the ultra-low permeability of the compacted reservoir. Studies show that methyl acetate not only acts as an acid carrier, but in the presence of water in the pore space is slowly hydrolyzed to methanol and acetic acid, which, in turn, reacts with the rock. This significantly prolongs the reaction time and has a positive effect on the well treatment process.

\section{References}

1. Kurovets, I. M., Mykhailov, V. A., Zeikan, O. Yu., Krupskyi, Yu. Z., Hladun, V. V., Chepil, P. M. et. al. (2014). Unconventional sources of hydrocarbons of Ukraine. Unconventional sources of hydrocarbons: problem review. Kyiv: Nika-tsentr, 208.

2. Vakarchuk, S. H., Dovzhok, T. Ye., Filiushkin, K. K. et. al. (2014). Perspektyoy osvoiennia resursiv hazu ushchilnenykh porid u Skhidnomu naftohazonosnomu rehioni Ukrainy. Kyiv: TOV «VTS PRYNT », 208

3. Dong, K., Zhu, D., Hill, A. D. (2018). The role of temperature on optimal conditions in dolomite acidizing: An experimental study and its applications. Journal of Petroleum Science and Engineering, 165, 736-742. doi: https://doi.org/10.1016/j.petrol. 2018.03.018

4. Chang, F. F., Nasr-El-Din, H. A., Lindvig, T., Qui, X. W. (2008) Matrix Acidizing of Carbonate Reservoirs Using Organic Acids and Mixture of $\mathrm{HCl}$ and Organic Acids. All Days. Denver: Richardson. doi: https://doi.org/10.2118/116601-ms

5. Zimin, O. L., Zezekalo, I. H., Bondar, H. M., Yevdoshchuk, M. I. (2019). Perspektyvy rozrobky ushchilnenykh karbonatnykh kolektoriv u mezhakh Dniprovsko-Donetskoi zapadyny. Naftohazova haluz Ukrainy, 2, 14-18.

6. Kalfayan, L. (2008) Production enhancement with acid stimulation. Tulsa: PennWell, 252.

7. Ali, M. T., Nasr-El-Din, H. A. (2020). New Insights into Carbonate Matrix Acidizing Treatments: A Mathematical and Experimental Study. SPE Journal, 25 (3), 1272-1284. doi: https:// doi.org/10.2118/200472-pa

8. Ali, M. T., Nasr-El-Din, H. A. (2018). A Robust Model To Simulate Dolomite-Matrix Acidizing. SPE Production \& Operations, 34 (1), 109-129. doi: https://doi.org/10.2118/191136-pa

9. Burton, R. C., Nozaki, M., Zwarich, N. R., Furui, K. (2019) Improved Understanding of Acid Wormholing in Carbonate Reservoirs through Laboratory Experiments and Field Measurements. SPE Journal, 25 (2), 587-608. doi: https://doi.org/ $10.2118 / 191625-\mathrm{pa}$

10. Harris, R. E., McKay, I. D., Mbala, J. M., Schaaf, R. P. (2001). Stimulation of a Producing Horizontal Well Using Enzymes that Generate Acid In-Situ - Case History. All Days. doi: https:// doi.org/10.2118/68911-ms

Oleh Zimin, Senior Lecturer, Department of Oil and Gas Engineering and Technology, National University «Yuri Kondratyuk Poltava Polytechnic», Poltava, Ukraine, e-mail.: ziminoleg2@gmail.com, ORCID: https://orcid.org/0000-0001-9281-0462 